\title{
Characteristics of Cuticular Wax and Analysis of Wax Biosynthesis Related Genes in Lanzhou Lily(Lilium Davidii Var. Unicolor) Under Drought Stress
}

\section{Wenmei Li}

Northwest Institute of Eco-Environment and Resources

\section{Yajun Wang}

Northwest Institute of Eco-Environment and Resources

\section{Yubao Zhang}

Northwest Institute of Eco-Environment and Resources

\section{Zhihong Guo}

Northwest Institute of Eco-Environment and Resources

\section{Yang Qiu}

Northwest Institute of Eco-Environment and Resources

Zhongkui Xie ( $\nabla$ wxhcas@lzb.ac.cn )

Northwest Institute of Eco-Environment and Resources

\section{Research article}

Keywords: Lanzhou lily, Drought stress, Cuticular wax, Fatty acid elongation, KCS

Posted Date: September 3rd, 2020

DOI: https://doi.org/10.21203/rs.3.rs-54576/v1

License: (c) (i) This work is licensed under a Creative Commons Attribution 4.0 International License.

Read Full License 


\section{Abstract}

Background: Plant wax is the general term of cuticle lipid components on the outer surface of plant tissue, which is closely related to drought resistance of plants. Lanzhou lily has the characteristics of wide adaptability, strong drought resistance, high ornamental and edible value. Plants were grown under three drought intensity treatments, namely, being watered at intervals of 5, 15, and 25 days. In this study, we analyzed the structure and component of cuticular wax of Lanzhou lily and Tresor under drought stress by scanning electron microscopy (SEM) and gas chromatography-mass spectrometry (GC-MS). We employed RNA sequencing (RNA-Seq) to investigate transcriptomic changes in the Lanzhou lily in response to drought stress.

Results: In present study, the wax crystals of Lanzhou lily were mainly irregular flakes and filaments, while the wax crystals of Tresor lily were mainly granular. There were four kinds of compounds in the cuticle wax of Lanzhou lily and Tresor lily, which were acids, esters, alkanes and alcohols. Among them, the main components of Lanzhou lily were alkanes, and the content of acids in Tresor lily was more. Phylogenetic tree analysis showed that KCS homologous gene TRINITY_ DN101578_c0_g3 and TRINITY _ DN98845_c1_g2 genes were clustered into one group, TRINITY_ DN95975_c0_g3 and dicotyledons were clustered into the same branch. In addition, transcriptome analysis of Lanzhou lily showed that the metabolic pathway of fatty acid elongation was significant under severe drought stress. KCS1, KCS3, KCS6 and KCS11 encoding fatty acid elongation were significantly expressed under moderate drought stress. The expression of MYB96 transcription factor was only significant under severe drought stress.

Conclusions: The wax content and components of Lanzhou lily were more than those of Tresor lily. Drought stress increased the wax content of Lanzhou lily and enhanced its drought resistance. Our research has revealed some important significant expression genes not only improved the drought tolerance of Lanzhou lily, but also had high application value in the development of drought tolerant varieties.

\section{Background}

Drought affects the normal growth of plants, disturbs the water relationship and reduces water use efficiency. Leaves are the main photosynthetic organs of plants and the main biomass of most agricultural crops. They are often seriously affected by environmental stress. Therefore, the accumulation of wax in leaves is an important physiological process[1]. In many morphological adaptations, waxiness of leaf epidermis plays a key role in improving plant drought tolerance by reducing water loss of cuticle[2]. Cuticular wax is mainly a mixture of very long chain fatty acids (VLCFAs, $>18$ carbons in length, chain lengths ranging from $\mathrm{C}_{20}$ to $\mathrm{C}_{34}$ ) and their derivatives, such as alkanes, alcohols, ketones, aldehydes, acids and esters, and aliphatic compounds, and has specific crystal forms, such as bread crumbs, flakes, columns, tubes, etc[3-4]. Cuticular wax is a kind of lipid existing outside the epidermis of leaves. Barthlott believed that there was a certain relationship between wax crystal structure and wax composition[5]. Wax in plant epidermis is insoluble in water and dissolves in organic solvents 
(chloroform, hexane, etc.), which is the first defensive physiological barrier for plants to isolate the external environment. Waxiness of plant epidermis plays an important role in improving drought tolerance[6-7], reducing water transpiration[8], reducing UV damage[9] and resisting diseases and insect pests[10].

Wax biosynthesis begins with the synthesis of very long chain fatty acids in plastids[11]. In most plants, there are two main pathways for wax biosynthesis: acyl reduction to produce primary alcohols and wax esters; decarburization leads to the formation of aldehydes, alkanes, secondary alcohols and ketones, and the carbon skeleton carbon atoms of the main products are odd. About $80 \%$ of plant waxes are synthesized by decarbonylation of VLCFAs, in which alkanes are the main products. In previous studies[11-12], the waxy components in the stem epidermis of Arabidopsis were synthesized by decarboxylation pathway, and a small amount of wax components were synthesized by acyl reduction pathway.

Lanzhou lily is sweet and refreshing, white as jade. It is a variety of Sichuan lily and the only edible sweet lily in China. Lanzhou lily obtained the bulblet seed ball through the underground bulblet differentiation to carry on the asexual reproduction. Lanzhou lily is mainly planted on the hillside without irrigation. Lanzhou lily has the characteristics of wide adaptability, strong drought resistance, high ornamental and edible value. Lanzhou lily and Tresor belong to Asiatic hybrids. Tresor lily resistance was stronger and the growth cycle was shorter. In our study, the crystal morphology of waxy compounds on the leaves of Lanzhou lily and Tresor were observed by SEM. The content and composition of cuticular wax of Lanzhou lily and Tresor were analyzed by GC-MS. Finally, we also used transcriptome sequencing to screen genes related to wax biosynthesis in Lanzhou lily. Our results were helpful to further explore the adaptation mechanism of Lanzhou lily under drought stress.

\section{Results}

\section{Leaf relative water and chlorophyll content (SPAD value) under drought stress}

Fig. 1a shows Lanzhou lily and Tresor under drought treatments. With the increase of drought stress, the leaf relative water and chlorophyll content (SPAD value) of Lanzhou lily and Tresor decreased (Fig. 1b,c). Under moderate drought stress, the chlorophyll content (SPAD value) of Lanzhou lily and Tresor decreased by $10.48 \%$ and $10.28 \%$ respectively compared to the control. When the severe treatment was applied, chlorophyll (SPAD) content in the Lanzhou lily and the Tresor lily both decreased significantly compared to the control group, namely, by $35.8 \%$ and $14.6 \%$ (Fig. 1c), respectively.

\section{Stomatal aperture in response to drought}

Our study found significant changes in the stomatal aperture of the Lanzhou lily and the Tresor lily under drought stress (Fig. 2). With an increase in the intensity of drought stress, the stomatal aperture and the density of these two lily genotypes exhibited a decreasing and increasing trend, respectively. Additionally, the stomatal density of the Lanzhou lily was higher compared to the Tresor lily(Fig. 2b). 


\section{SEM observation of the waxy layer under drought stress}

Fig. 3 shows the waxy crystal structure of the epidermis of the leaves of Lanzhou lily and Tresor. The wax crystal types of leaf epidermis of two lilies were different. Among them, the waxy crystals of Lanzhou lily were mainly irregular flaky and filiform, and the granular crystals were less and have no specific direction. However, the wax crystal of Tresor lily was mainly granular.

\section{Effect of drought stress on wax content of Lanzhou lily}

The cuticle wax of Lanzhou lily and Tresor mainly contains 4 kinds of compounds, mainly acids, esters, alkanes and some alcohols (Fig. 4). Lanzhou lilies were mainly alkanes, while Tresor were mainly acids. With the increase of drought stress, the cuticle wax content of Lanzhou lily and Tresor increased gradually. Under moderate drought stress, the total wax content of Lanzhou lily and Tresor was $9.86 \mu \mathrm{g} /$ $\mathrm{cm}^{2}$ and $3.62 \mu \mathrm{g} / \mathrm{cm}^{2}$, respectively, which increased by $27.72 \%$ and $32.25 \%$ compared with the control (Fig. 4d). Under severe drought stress, Lanzhou lily and Tresor total wax content were $10.21 \mu \mathrm{g} / \mathrm{cm}^{2}$ and $4 \mu \mathrm{g} / \mathrm{cm}^{2}$, respectively, significantly increased by $50.83 \%$ and $66.67 \%$ compared with the control. Under moderate drought stress, the acids, esters and alkanes of Lanzhou lily accounted for $31.03 \%, 1.32 \%$ and $62.78 \%$ of the total amount of wax, while the acids, esters and alkanes of Tresor accounted for $82.32 \%$, $11.33 \%$ and $5.8 \%$ of the total amount of wax, respectively (Fig.4a,b,c).

Further qualitative analysis showed that there were 15 kinds of waxy components in Lanzhou lily and 9 kinds of waxy components in Tresor (Table 1), but the distribution of carbon chain of waxy components was consistent under different treatments. Table 3 shows that there are $C_{29}, C_{31}$ and $C_{33}$ in Lanzhou lily, and the increase of alkane content was mainly concentrated in the high carbon number $\left(C_{29}-C_{33}\right)$ alkane component. Under control treatment, the content of $\mathrm{C}_{29}$ alkanes in straight chain alkanes was the highest among all the waxes in Lanzhou lily. Under moderate and severe drought stress, the content of $\mathrm{C}_{31}$ alkanes in straight chain alkanes was the highest among all the waxes in Lanzhou lily.

\section{Different gene expression during drought stress}

To elucidate the response of Lanzhou lily to drought stress, we identified the DEGs in Lanzhou lily under control, moderate and severe drought treatments. There were 3104 DEGs in C vs. MS comparisons. Total of 1965 genes in C vs. S, and 668 and 1297 genes in C vs. S were specifically up-regulated and downregulated. Furthermore, we could identify 6 common genes through the Venn diagram (Fig. 5) during the different three comparison period in drought treatment.

\section{Response of Lanzhou lily KEGG passway to drought stress}

Fig. 6 shows the KEGG pathway of Lanzhou lily under moderate and severe drought stress. The metabolic pathway of fatty acid elongation was not significant under moderate drought stress (Fig. 6a). Under severe drought stress, the metabolism pathway of fatty acid elongation in Lanzhou lily was significantly and the abundant factors were increased(Fig. 6b), which indicated that the DEG involved in 
fatty acid elongation might play a very important role in the accumulation of cuticular wax in Lanzhou lily.

\section{Differential expression of waxy genes}

The changes of wax in plant epidermis caused by drought stress are mainly realized by changing the expression of genes related to wax synthesis. Table 2 shows the fatty acid elongation related gene expression of Lanzhou lily under drought stress. KCS (3-ketoyl COA synthetase), five genes encoding fatty acid elongation metabolism, were down regulated under moderate drought stress, while a gene encoding fatty acid elongation was inhibited under severe drought stress. With the increase of drought stress and the expression of KCS decreased, which indicated that drought stress seriously affected the expression of genes related to wax synthesis in Lanzhou lily. There are 8 genes encoding fatty acid degradation metabolism under moderate drought stress, among which 7 genes were down-regulated and 1 was upregulated. However, there are only 3 genes encoding fatty acid degradation under severe drought stress, 2 of which were down regulated and 1 was up-regulated (Table 2). The MYB96 transcription factor directly up regulates cuticle wax biosynthesis enzyme gene to induce cuticle wax biosynthesis and affects plant drought resistance[13-14]. The significant expression of MYB96 transcription factor induced the biosynthesis of cuticle wax and enhanced the drought tolerance of Lanzhou lily under severe drought stress.

\section{Phylogenetic tree analysis}

Fig. 7 shows the phylogenetic tree of KCS amino acids in Lanzhou lily. TRINITY_ DN83344_c0_g1 and KCS (025807245) of peanut were clustered into one group and had the closest relationship. TRINITY_ DN95975_ c0_ g3 and dicotyledons such as Chinese rose, Rhodiola and Petunia were clustered into the same branch, while monocotyledons were clustered into different branches, and their genetic relationship was the farthest. KCS homologous gene TRINITY _ DN101578_c0_g3 and TRINITY _ DN98845_c1_g2 genes were clustered into one group.

\section{Fatty acid biosynthesis}

Very long chain fatty acids (VLCFAs) are fatty acids with more than $18 \mathrm{C}$ carbon atoms[15]. Most VLCFAs with 16 or longer carbon chains fatty acids, and their biosynthesis is mostly in endoplasmic[16]. It is involved in the synthesis of seed glycerides, biofilm lipids and sphingolipids, and provides precursors for the biosynthesis of cuticular wax[17]. 3-ketoacyl-CoA synthase (KCS) [EC:2.3.1.199] is a key enzyme in the biosynthesis of very long chain monounsaturated fatty acids. Fig. 8 shows the impact of drought stress on the synthesis of cutin, suberin and wax of Lanzhou lily. KCS was significantly down regulated under moderate and severe drought stress, which indicated that the decrease of VLCFAs induced by drought stress further affected the biosynthesis of cutin, suberin and wax. Under moderate drought stress, 5 genes encoding KCS were down regulated at transcriptional level, while 1 gene was inhibited under severe drought stress, and only 4 genes encoding KCs were down regulated at transcriptional level. 


\section{Discussion}

Wax form a unique three-dimensional structure on the plant surface. The size and location of waxy crystals on the plant surface play an important role in determining the water diffusion pathway[18]. In our study, we found that the epidermis of two kinds of lily leaves was covered with obvious waxy crystals by scanning electron microscopy. Among them, Lanzhou lily embedded in the waxy layer in irregular filaments and flakes, while Tresor was granular. In addition, under drought stress, the number of wax crystals in the epidermis of the two lily leaves increased significantly compared with the control group (Fig. 3), which shows that the wax in the epidermis can be synthesized by wax and deposited into crystals in the leaf epidermis to increase the number of crystals in response to drought stress.

Many characteristics of leaves, such as water potential, osmotic regulation, cell membrane stability, cuticular wax and conductance affect the drought resistance of plants[19]. Among them, the increase of plant wax content is related to the increase of drought resistance[20-21]. Premchandra found that the content and thickness of wax in plant epidermis impacted the water transpiration of plants[22]. In our study, the wax content in the leaves of Lanzhou lily and Tresor increased with the increase of drought stress, which was similar to that of Arabidopsis[23], sesame[24], tomato[25]and soybean[26] plants under drought stress. The total wax content of Lanzhou lily increased under drought stress, but the relative components did not change, which was consistent with tree tobacco leaves (Nicotiana glauca)[27]. Alkanes were the main components of wax in Lanzhou lily leaves. In our study, the alkanes content in Lanzhou lily leaves increased significantly during drought, and the main alkanes were $\mathrm{C}_{29}, \mathrm{C}_{31}$ and $\mathrm{C}_{33}$. Kosma found that the wax content in the epidermis of Arabidopsis increased by $75 \%$, the paraffin wax content increased by $93 \%$, and it was mainly super long chain alkane, which was consistent with our results[28]. The water loss of plant leaf epidermis was inseparable from alkanes[29]. The above results indicate that alkanes may play an important role in limiting the transpiration of water in the cuticle of Lanzhou lily leaves, and enhance its drought resistance.

Fatty acid elongation pathway is located in the upstream of cutin, suberine, and wax biosynthesis, which provides substrates for the biosynthesis of long fatty acid cutin and wax. KEGG pathway enrichment analysis showed that the biosynthesis pathway of fatty acid elongation was significantly enriched under severe drought stress (Fig. 6b). The changes of wax content in plant epidermis induced by drought stress were mainly realized by changing the expression of genes related to wax synthesis. KCS was a rate limiting enzyme for the synthesis of very long chain fatty acids[30]. Previous studies have found that KCS1 was involved in wax biosynthesis[31], and KCS6 overexpression can increase the cuticular wax in Arabidopsis thaliana[32]. Lacking KCS gene can result in the inhibition of $\mathrm{C}_{22}$ fatty acid chain extension and the decrease of $\mathrm{C}_{22}$ and $\mathrm{C}_{24}$ ultra long chain fatty acid content[33]. Very long chain fatty acids are precursors of wax synthesis in plant epidermis, and KCS gene encoding $\beta$-ketoacylcoa condensation enzyme was the key gene for the synthesis of very long chain fatty acids. In the present study, with the increase of drought, the expression of KCS1 and KCS11 decreased, but the wax components of Lanzhou lily remained unchanged. Previous studies showed that the loss of KCS1 did not lead to the complete loss of any single wax component or significantly reduce the total wax content[34]. KCS1 and KCS11 genes 
have similar functions. MYB96 transcription factor regulates stomatal opening and cuticle transpiration. In addition, stress response transcription factor MYB96 plays an active role in inducing the expression of wax synthesis genes in Arabidopsis[35]. MYB96 transcription factor serves as a molecular network to integrate drought stress signals and promote fatty acid elongation in cuticle wax biosynthesis[13]. MYB96 transcription factor was not expressed under moderate drought stress of Lanzhou lily leaves, but was significantly expressed under severe drought stress, which indicated that MYB96 transcription factor was induced by severe drought to promote cuticle wax biosynthesis to resist drought.

\section{Conclusions}

Lanzhou lily is a drought tolerant plant, mainly growing in arid and semi-arid areas. In this study, we analyzed the structure and content of cuticular wax of Lanzhou lily and Tresor under moderate and severe drought stress by scanning electron microscopy (SEM) and gas chromatography-mass spectrometry (GC-MS). The wax crystals of Lanzhou lily were mainly irregular flakes and filaments, while the wax crystals of Tresor lily were mainly granular. There were four kinds of compounds in the cuticle wax of Lanzhou lily and Tresor lily, which were acids, esters, alkanes and alcohols. Among them, the main components of Lanzhou lily were alkanes, and the content of acids in Tresor lily was more. We employed RNA sequencing (RNA-Seq) to investigate transcriptomic changes in the Lanzhou lily in response to drought stress.

Approximately 63,314 of unigenes were annotated in a sequence similarity search of six (GO, COG, KEGG, Swissprot, KOG, and NR) public databases. We identified 3104 and 1965 DEGs in C vs. MS and C vs. $s$ comparisons, respectively. Kcs1, kcs3, kcs6 and kcs11 encoding fatty acid elongation were significantly expressed under moderate drought stress.

\section{Methods}

\section{Plant growth conditions and drought treatment}

For this study, we selected the Lanzhou lily and the Tresor lily for our comparative experiment. Lanzhou lily bulbs were purchased in the West Orchard of Lanzhou City, Gansu Province, and Tresor were purchased in Xiwang Flower Seed Industry Co., Ltd. A voucher specimen of Lanzhou lily was deposited at the Northwest Institute of Eco-environment and Resource, Chinese Academy of Sciences (number LZ 00321). The experiment was carried out in Gaolan Research Station under the auspice of the Chinese

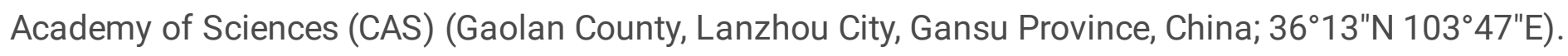
This area is a typical Semi-arid Loess Hilly and gully area with dry and rainless climate. It is a warm temperate semi-arid continental monsoon climate with an altitude of about $2100 \mathrm{~m}$, an annual average temperature of $6.8^{\circ} \mathrm{C}$.

Lanzhou lily and Tresor were grown in greenhouses, with ventilation on both sides of the shed, which only prevented rain. The experiment was carried out in the way of barrel planting. $7 \mathrm{~kg}$ of substrate (soil: peat 
soil $=3: 1$ ) was packed in the same plastic barrel (specification $24 \mathrm{~cm} \times 28 \mathrm{~cm}$ ). Lily bulbs with the same size were selected and transferred into the barrel, and the bulbs were buried about 2-3 cm under the substrate.

Drought stress treatment: the experiment adopted completely random design, determined the soil water content by drying method, and determined the intensity of drought stress according to the soil water content and stress days. There were three treatments, namely control group (c), moderate stress (MS) and severe stress $(\mathrm{s})$. The actual soil moisture content was $(12 \pm 1.23) \%,(8 \pm 1.3) \%$ and $(6 \pm 0.7) \%$, respectively. The experiment started in March 2019, and began to harvest at the end of the whole growth cycle. Five plants were planted per barrel, 90 barrels for each variety, and 15 repetitions for each treatment. Before the drought treatment, all the treatments should be watered with enough water to ensure the emergence of seed balls. After the emergence rate reaches $99 \%$, the water control treatment should be carried out after one-time quantitative irrigation. At 50 days of drought stress, the middle healthy leaves were taken to measure the indexes.

\section{Measurement of physiological indexes}

The leaf relative water content was determined according to the method established by Barrs and Weatherley (1962)[36]. Chlorophyll concentrations (determined using the soil plant analysis development (SPAD) value) were measured using a SPAD 502 Plus Chlorophyll Meter (Konica Minolta, Inc., Sakai City, Osaka, Japan). Stomatal apertures were observed using light microscope (Leica DM750) following 50 days of the drought stress treatments. Stomata were counted in 5 randomly selected microscope fields, and each sample was repeated three times.

\section{Scanning electron microscopy (SEM)}

Lanzhou lily and Tresor of leaf were cut along the leaf vein from the middle, divided into positive and negative sides. The samples were cut at a distance of $0.5 \mathrm{~cm}$ from the middle leaf vein, fixed in a test tube with glutaraldehyde and then dried in an oven at $40{ }^{\circ} \mathrm{C}$, and cut into $3 \mathrm{~mm} \times 3 \mathrm{~mm}$ placed in the coater to spray gold coating. The morphology was observed under the scanning electron microscope (S3000-N, Hitachi, Tokyo, Japan).

\section{Wax extraction}

We extracted the wax according to the previous method[37]. Five lily plants with the same growth condition were selected from the control group and the drought stress group. The leaves in the middle of two kinds of lilies were separated with scissors, and the leaf area was determined rapidly. The leaves were immersed in $30 \mathrm{ml}$ chloroform at room temperature immediately, shaken gently for $1 \mathrm{~min}$, and then the leaves were taken out. Then $20 \mu \mathrm{L} \mathrm{C}_{24}$ alkanes were added into the extraction solution as internal standard. After the chloroform in the sample bottle was dried with nitrogen, $40 \mu \mathrm{L}$ pyridine was added to dissolve the wax, and then the derivative BSTFA of the same volume was added. The derivative was 
performed in a metal bath at $70{ }^{\circ} \mathrm{C}$ for $30 \mathrm{~s}$. Dry the derivative reagent with nitrogen, dissolve the product in $1 \mathrm{ml}$ of chloroform, and transfer it into a sample bottle for GC-MS analysis.

\section{Wax components analysis}

The wax content was determined by gas chromatograph (AOC-20i, GC-2010, E). Using GC-MS to detect the waxy components in the control group to get the ion peaks of various waxy compounds, and then through the retrieval of the mass spectrometry database to identify various compounds to get the standard sample map. After GC-FID was used to detect each sample, the ion peak of wax component was deduced according to the reference diagram, and then the ion peak area was obtained by integrating the ion peak with laboratory software, then the various compounds were quantitatively analyzed according to the internal standard peak area and the content of $\mathrm{C}_{24}$ added. GC-MS and GC-FID: injection volume $2 \mu \mathrm{L}$, injection temperature $280{ }^{\circ} \mathrm{C}$, split ratio $5: 1$, detector temperature $320^{\circ} \mathrm{C}$.

\section{Phylogenetic tree analysis of KCS gene}

We used NCBI (http://www.ncbi.nlm.nih.gov/blast/) biological software for amino acid multi sequence alignment analysis to find homologous genes in Lanzhou lily and other species, and used Mega 5.0 to construct phylogenetic tree of amino acid sequences by neighbor joining method.

\section{RNA extraction and construction of cDNA library}

Total RNA was extracted from frozen leaves of 9 plants of three independent biological replicates with rnaprep plant Kit (tlangen biotechnology Beijing) according to the instructions of the kit. The purity, concentration and integrity of RNA samples were detected by nanodrop and Agilent 2100 Bioanalyzer (Agilent Technologies, Inc.). Adaptor sequences and low quality reads were removed, mRNA was enriched by oligo (dT) beads and then cleaved into short fragments using fragmentation buffer. Using mRNA as template, the first cDNA strand was synthesized by random hexamers, the second cDNA was synthesized by buffer, dNTPs, RNase $\mathrm{H}$ and DNA polymerase $\mathrm{I}$, the cDNA was purified by AMPureXPbeads, the purified double cDNA was repaired at the end, followed by the addition of poly-(A) tails and ligation to lllumina sequencing adapters, and then the fragment size was selected by AMPure XPbeads. Finally, the cDNA library was obtained by PCR enrichment. After the sample was tested to be qualified, the library was constructed. High quality clean data of $211.64 \mathrm{~GB}$ was obtained, and the percentage of base Q30 reached $90.53 \%$ (Table 3). The clean data were combined in order to obtain the single gene library of the species. Through the assembly of Trinity software, 324081 transcripts and 142191 single genes were obtained (Table 4).

\section{Differentially expressed genes (DEGs) analysis}

BowTie software was used to compare sequencing reads and UniGene library sequences, while RSEM was used to estimate their combined expression levels[38]. Fragments Per Kilobase of transcript per Million mapped reads (FPKM) were used to represent the expression abundance of the corresponding 
UniGene sequences. The log2 (fold change) $\geq 1$ and the false discovery rate (FDR) $<0.05$ thresholds were used to obtain statistically significant gene expression differences.

\section{Statistical analyses}

The data were analyzed by Excel and spass 16.0 software with mean \pm standard error. One way ANOVA was used to compare the differences. Duncan's method was used to test the difference of wax content between varieties and treatments. We defined significance at $P<0.05$.

\section{Abbreviations}

C: control; MS: moderate severe; S: severe; RNA sequencing; DEGs: Differentially expressed genes; KEGG: Kyoto Encyclopedia of Genes and Genomes; FPKM: The fragments per kb per million reads; FDR: False discovery rate.

\section{Declarations}

\section{Authors' contributions}

ZKX conceived the project and revised the manuscript; YJW, ZHG, YBZ and YQ performed the experiments with the help of WML; WML wrote the paper. All authors read and approved the final manuscript.

\section{Funding}

The authors of this study would like to thank the Major Science \& Technology projects of Gansu Province (182D2NA010), the Science and Technology Service Network Initiative of the Chinese Academy of Sciences (KFJ-STS-QYZD-120), the Key R\&D plan of the Ningxia Hui Autonomous Region (2019BBF02018) for funding.

\section{Availability of data and materials}

The datasets used and analyzed during the current study are available from the corresponding author on reasonable request.

\section{Ethics approval and consent to participate}

The use of plants in this study conforms to international, national and/or institutional guidelines.

\section{Acknowledgements}

Not applicable.

\section{Consent for publication}

Not applicable. 


\section{Competing interests}

The authors declare that they have no conflict of interest.

\section{References}

1. Jenks M A, Joly R J, Peters PJ, Rich PJ, Ashworth EN. Chemically induced cuticle mutation affecting epidermal conductance to water vapor and disease susceptibility in Sorghum bicolor (L.) Moench. Plant Physiol. 1994; 105(4): 1239-1245.

2. Samdur MY, Manivel P, Jain VK, Chikani BM, Misra JB. Genotypic differences and water deficit induced enhancement in epicuticular wax load in peanut. Crop Sci. 2003; 43: 1294-1299.

3. Lee SB, Suh MC. Advances in the understanding of cuticular waxes in Arabidopsis thaliana and crop species. Plant Cell Rep. 2015; 34(4): 557-572.

4. Samuels $L$, Kunst $L$, Jetter R. Sealing plant surfaces: cuticular wax formation by epidermal cells. Annu. Rev. Plant Biol. 2008; 59: 683 -707.

5. Barthlott W, Neinhuis C, Cutler D, Ditsch F, Meuse I, Theisen I, Wilhelmil H. Classification and terminology of plant epicuticular waxes. Bot J Linn Soc. 1998; 126(3): 237-260.

6. Yang M, Yang Q Y, Fu T D, Zhou Y. Overexpression of the Brassica napus BnLAS gene in Arabidopsis affects plant development and increases drought tolerance. Plant Cell Rep. 2011; 30(3):373-388.

7. Broun P, Poindexter P, Osborne E, Jiang CZ, Riechmann JL. WIN1, a transcriptional activator of epidermal wax accumulation in Arabidopsis. P Natl Acad Sci USA. 2004; 101: 4706-4711.

8. Kosma D K, Parsons U P, Isaacson T, Shiyou Lü, Jenks MA. Fruit cuticle lipid composition during development in tomato ripening mutants. Physiol Plantarum, 2010; 139:107-117.

9. Krauss P, Markstädter C, Riederer M. Attenuation of UV radiation by plant cuticles from woody species. Plant Cell Environ. 2010;20(8): 1079-1085.

10. Isaacson T, Kosma DK, Matas AJ, Buda GJ, Rose JK. C Cutin deficiency in the tomato fruit cuticle consistently affects resistance to microbial infection and biomechanical properties, but not transpirational water loss. The Plant Journal. 2009; 60(2): 363- 377.

11. Kunst L, Samuels L. Plant cuticles shine: advances in wax biosynthesis and export. Curr Opin Plant Biol.2009;12(6): 721-727.

12. Bernard A, Joubes J. Arabidopsis cuticular waxes: advances in synthesis, export and regulation. Prog Lipid Res. 2013;52(1): 110-129.

13. Lee SB, Kim HU, Suh MC. MYB94 and MYB96 additively activate cuticular wax biosynthesis in arabidopsis. Plant Cell Physiol. 2016;57: 2300-2311.

14. Pil Joon Seo, Chung-Mo Park. Cuticular wax biosynthesis as a way of inducing drought resistance. Plant Signal Behav. 2011; 6: 1043-1045.

15. Murphy DJ, Mukherjee KD. Biosynthesis of triacylglycerols containing very long chain acyl moieties in seeds. Biological Role of Plant Lipids.1989;143囚146. 
16. Jakobsson A, Westerberg R, Jacobsson A. Fatty acid elongases in mammals: their regulation and roles in metabolism. Prog Lipid Res. 2006; 45: 237-249.

17. Kunst L, Samuels AL. Biosynthesis and secretion of plant cuticular wax. Prog Lipid Res. 2003; 42(1): 51-80.

18. Burghardt M, Riederer M. Cuticular transpiration. Biology of the plant cuticle. Oxford:Black well Publishing, 2002.

19. Islam MA, Du H, Ning J,Ye H, Xiong L. Characterization of Glossy1-homologous genes in rice involved in leaf wax accumulation and drought resistance. Plant Mol Biol. 2009; 70:443-456.

20. Guo J, Xu W, Yu XC, Shen H, Li HS, Cheng DG, Liu AF, Liu JJ, Liu C, Zhao SJ,Song JM. Cuticular wax accumulation is associated with drought tolerance in wheat near-isogenic lines. Front. Plant Sci. 2016; 7: 1809.

21. Zhou AM, Liu EH, Liu J. Characterization of increased cuticular wax mutant and analysis of genes involved in wax biosynthesis in Dianthus spiculifolius. Hortic Res-Eengland. 2018; 5(4).

22. Premachandra GS, Saneoka H, Kounosuke F, Shoitsu O. Leaf water relations, osmotic adjustment, cell membrane stability, epicuticular wax load and growth as affected by increasing water deficits in Sorghum. J Exp Bot. 1992; 43(12):1569-1576.

23. Jenks MA, Eigenbrode SD, Lemieux B. Cuticular waxes of Arabidopsis. In: Somerville CR, Meyerowitz EM (eds) The Arabidopsis book. American Society of Plant Biologists, Rockville, MD, 2002.

24. Kim KS, Park SH, Jenks MA. Changes in leaf cuticular waxes of sesame (Sesamum indicum L.) plants exposed to water deficit. J Plant Physiol. 2007;164: 1134-1143.

25. Kosma DK, Parsons EP, Isaacson T, Shiyou Lü, Jenks MA. Fruit cuticle lipid composition during development in tomato ripening mutants. Physiol Plantarum. 2010; 139 :107-117.

26. Kim K, Park S, Jenks MA. Influence of water deficit on leaf cuticular waxes of soybean. Int J Plant Sci. 2007; 168(3): 307-316.

27. Cameron KD, Teece MA, Smart LB. Increased accumulation of cuticular wax and expression of lipid transfer protein in response to periodic drying events in leaves of tree tobacco. Plant Physiol. 2006;140: 176- 183.

28. Kosma DK, Bourdenx B, Bernard A, Parsons E P, Lu S, Joubes J, Jenks MA. The impact of water deficiency on leaf cuticle lipids of Arabidopsis. Plant Physiol. 2009; 151: 1918-1929.

29. Oliverira AFM, Meirelles ST, Salation A. Epicuticular waxes from caatinga and cerrado species and their efficiency against water loss. An Acad Bras Cienc. 2003;75(4):431-439.

30. Millar AA, Kunst L. Very-long-chain fatty acid biosynthesis is controlled through the expression and specificity of the condensing enzyme. Plant J. 1997; 12(1): 121-131.

31. Lee SB, Suh MC. Recent advances in cuticular wax biosynthesis and its regulation in Arabidopsis. Mol Plant. 2013; 6(2): 246-249.

32. Hooker TS, Millar AA, Kunst L. Significance of the expression of the CER6 condensing enzyme for cuticular wax production in Arabidopsis. Plant Physiol. 2002;129(4): 1568-1580. 
33. Lee SB, Jung SJ, Go YS, Kim HU, Kim JK, Cho HJ, Park OK, Suh MC. Two Arabidopsis 3-ketoacylCoA synthase genes, KCS20 and KCS2/DAISY, are functionally redundant in cuticular wax and root suberin biosynthesis, but differentially controlled by osmotic stress, Plant J. 2009; 60 (3): 462-475.

34. Todd J, Post-Beittenmiller D, Jaworski JG. KCS1 encodes a fatty acid elongase 3-ketoacyl-CoA synthase affecting wax biosynthesis in Arabidopsis thaliana. Plant J. 2010;17(2):119-130.

35. Seo PJ, Lee SB, Suh MC, Park MJ, Go YS, Park CM. The MYB96 transcription factor regulates cuticular wax biosynthesis under drought conditions in Arabidopsis. Plant Cell. 2011; 23:1138-1152.

36. Barrs HD, Weatherley PE. A re-examination of the relative turgidity technique for estimating water deficits in leaves. Aust. J. Biol. Sci. 1962;15: 413-428.

37. Zhou Q, Li C, Mishina K, Zhao JC, Zhang JW, Duan RJ, Ma XY, Wang AD, Meng QX, Komatsuda $T$, Chen GX. Characterization and genetic mapping of the $\beta$-diketone deficient eceriferum-b barley mutant. Theor Appl Genet. 2017; 130(6):1169.

38. Li B, Colin ND. RSEM: accurate transcript quantification from RNA-Seq data with or without a reference genome. BMC Bioinformatics. 2011; 12:323.

\section{Tables}


Table 1

Wax components and contents of the epidermis of Lanzhou lily and tresor under drought stress. Values are the means $\pm S D(n=3)$ (ANOVA followed by Duncan's multiple-range tests $(P<0.05))$. Drought stress:

C, control; MS, moderate stress; S, severe stress.

\begin{tabular}{|c|c|c|c|c|c|c|}
\hline \multirow[t]{2}{*}{ Compound name } & \multicolumn{3}{|c|}{$\begin{array}{l}\text { Lanzhou lily wax content } \\
\left(\mu \mathrm{g} / \mathrm{cm}^{2}\right)\end{array}$} & \multicolumn{3}{|c|}{$\begin{array}{l}\text { Tresor wax content } \\
\left(\mu \mathrm{g} / \mathrm{cm}^{2}\right)\end{array}$} \\
\hline & C & MS & $S$ & C & MS & $S$ \\
\hline Propanedioic acid,ethyl- & $\begin{array}{l}0.02 \pm \\
0.00\end{array}$ & $\begin{array}{l}0.03 \pm \\
0.00\end{array}$ & $\begin{array}{l}0.07 \pm \\
0.00\end{array}$ & - & - & - \\
\hline Decandioic acid & $\begin{array}{l}0.56 \pm \\
0.11\end{array}$ & $\begin{array}{l}0.08 \pm \\
0.00\end{array}$ & $\begin{array}{l}0.12 \pm \\
0.03\end{array}$ & - & - & - \\
\hline Nonacosanoic acid & $\begin{array}{l}0.41 \pm \\
0.05\end{array}$ & $\begin{array}{l}0.59 \pm \\
0.06\end{array}$ & $\begin{array}{l}0.55 \pm \\
0.09\end{array}$ & - & - & - \\
\hline Hexadecanoic acid & $\begin{array}{l}0.11 \pm \\
0.01\end{array}$ & $\begin{array}{l}0.10 \pm \\
0.02\end{array}$ & $\begin{array}{l}0.27 \pm \\
0.02\end{array}$ & $\begin{array}{l}0.15 \pm \\
0.01\end{array}$ & $\begin{array}{l}0.43 \pm \\
0.03\end{array}$ & $\begin{array}{l}0.46 \pm \\
0.05\end{array}$ \\
\hline Mannonic acid & $\begin{array}{l}0.01 \pm \\
0.00\end{array}$ & $\begin{array}{l}0.29 \pm \\
0.08\end{array}$ & $\begin{array}{l}0.19 \pm \\
0.06\end{array}$ & $\begin{array}{l}0.03 \pm \\
0.00\end{array}$ & $\begin{array}{l}0.05 \pm \\
0.00\end{array}$ & $\begin{array}{l}0.02 \pm \\
0.00\end{array}$ \\
\hline Octadecanoic acid & $\begin{array}{l}0.15 \pm \\
0.08\end{array}$ & $\begin{array}{l}0.12 \pm \\
0.02\end{array}$ & $\begin{array}{l}0.39 \pm \\
0.01\end{array}$ & $\begin{array}{l}0.24 \pm \\
0.02\end{array}$ & $\begin{array}{l}0.76 \pm \\
0.08\end{array}$ & $\begin{array}{l}0.80 \pm \\
0.09\end{array}$ \\
\hline Tricosanoic acid & $\begin{array}{l}0.20 \pm \\
0.02\end{array}$ & $\begin{array}{l}0.12 \pm \\
0.09\end{array}$ & $\begin{array}{l}0.16 \pm \\
0.07\end{array}$ & $\begin{array}{l}0.04 \pm \\
0.00\end{array}$ & $\begin{array}{l}0.05 \pm \\
0.01\end{array}$ & $\begin{array}{l}0.06 \pm \\
0.00\end{array}$ \\
\hline Pentacosanoic acid & $\begin{array}{l}1.07 \pm \\
0.09\end{array}$ & $\begin{array}{l}0.71 \pm \\
0.07\end{array}$ & $\begin{array}{l}0.85 \pm \\
0.06\end{array}$ & $\begin{array}{l}0.25 \pm \\
0.04\end{array}$ & $\begin{array}{l}0.25 \pm \\
0.09\end{array}$ & $\begin{array}{l}0.39 \pm \\
0.04\end{array}$ \\
\hline Heptacosanoic acid & $\begin{array}{l}0.72 \pm \\
0.05\end{array}$ & $\begin{array}{l}0.67 \pm \\
0.03\end{array}$ & $\begin{array}{l}0.76 \pm \\
0.10\end{array}$ & $\begin{array}{l}0.68 \pm \\
0.07\end{array}$ & $\begin{array}{l}0.88 \pm \\
0.01\end{array}$ & $\begin{array}{l}1.0 \pm \\
0.03\end{array}$ \\
\hline Nonacosanoic acid & $\begin{array}{l}0.30 \pm \\
0.02\end{array}$ & $\begin{array}{l}0.36 \pm \\
0.05\end{array}$ & $\begin{array}{l}0.36 \pm \\
0.03\end{array}$ & $\begin{array}{l}0.36 \pm \\
0.04\end{array}$ & $\begin{array}{l}0.56 \pm \\
0.09\end{array}$ & $\begin{array}{l}0.58 \pm \\
0.04\end{array}$ \\
\hline Mannonic acid,lactone & $\begin{array}{l}0.09 \pm \\
0.01\end{array}$ & $\begin{array}{l}0.06 \pm \\
0.00\end{array}$ & $\begin{array}{l}0.06 \pm \\
0.00\end{array}$ & - & - & - \\
\hline $\begin{array}{l}\text { Hexadecanoic acid,2.3-bis- } \\
\text { (hexadecyloxy)propyl ester }\end{array}$ & - & - & - & $\begin{array}{l}0.41 \pm \\
0.08\end{array}$ & $\begin{array}{l}0.41 \pm \\
0.04\end{array}$ & $\begin{array}{l}0.28 \pm \\
0.02\end{array}$ \\
\hline D-Mannitol & $\begin{array}{l}0.25 \pm \\
0.02\end{array}$ & $\begin{array}{l}0.49 \pm \\
0.03\end{array}$ & $\begin{array}{l}0.18 \pm \\
0.02\end{array}$ & $\begin{array}{l}0.02 \pm \\
0.00\end{array}$ & $\begin{array}{l}0.02 \pm \\
0.00\end{array}$ & $\begin{array}{l}0.04 \pm \\
0.00\end{array}$ \\
\hline Myo-Inositol & $\begin{array}{l}0.74 \pm \\
0.03\end{array}$ & $\begin{array}{l}0.98 \pm \\
0.08\end{array}$ & $\begin{array}{l}0.58 \pm \\
0.01\end{array}$ & $\begin{array}{l}0.21 \pm \\
0.05\end{array}$ & $\begin{array}{l}0.21 \pm \\
0.04\end{array}$ & $\begin{array}{l}0.36 \pm \\
0.09\end{array}$ \\
\hline Nonacosane & $\begin{array}{l}1.24 \pm \\
0.35\end{array}$ & $\begin{array}{l}1.60 \pm \\
0.37\end{array}$ & $\begin{array}{l}1.88 \pm \\
0.35\end{array}$ & - & - & - \\
\hline Hentriacontane & $\begin{array}{l}1.11 \pm \\
0.40\end{array}$ & $\begin{array}{l}2.54 \pm \\
0.60\end{array}$ & $\begin{array}{l}2.64 \pm \\
0.66\end{array}$ & - & - & - \\
\hline
\end{tabular}




\begin{tabular}{|lllllll|}
\hline Compound name & \multicolumn{3}{l|}{$\begin{array}{l}\text { Lanzhou lily wax content } \\
\left(\mu \mathrm{g} / \mathrm{cm}^{2}\right)\end{array}$} & \multicolumn{3}{l|}{$\begin{array}{l}\text { Tresor wax content } \\
\left(\mu \mathrm{g} / \mathrm{cm}^{2}\right)\end{array}$} \\
\cline { 2 - 7 } & C & MS & S & C & MS & S \\
\hline Tritriacontane & $0.64 \pm$ & $1.08 \pm$ & $1.12 \pm$ & - & - & - \\
\hline
\end{tabular}

Table 2

Changes of fatty acid elongation and degradation related gene expression in Lanzhou lily under drought stress

\begin{tabular}{|lllll|}
\hline Genes ID & Regulated & Fold change & Annotation \\
& & $\begin{array}{c}\text { C vs. MS C } \\
\text { vs. S }\end{array}$ & \\
\hline TRINITY_DN101578_c0_g3 & down & -1.63 & -1.49 & 3-ketoacyl-CoA synthase11 \\
\hline TRINITY_DN88964_c0_g1 & down & -1.65 & -1.61 & 3-ketoacyl-CoA synthase11 \\
\hline TRINITY_DN95975_c0_g3 & down & -1.47 & -1.45 & 3-ketoacyl-CoA synthase 1 \\
\hline TRINITY_DN98845_c1_g2 & down & -1.80 & -1.66 & 3-ketoacyl-CoA synthase 6 \\
\hline TRINITY_DN83344_c0_g1 & down & -2.01 & - & 3-ketoacyl-CoA synthase 3 \\
\hline TRINITY_DN101349_c1_g1 & down & -1.07 & - & enoyl-CoA hydratase \\
\hline TRINITY_DN102649_c0_g1 & down & -1.64 & -1.07 & Alcohol dehydrogenase, putative \\
\hline TRINITY_DN104142_c1_g1 & down & -1.05 & - & alcohol dehydrogenase \\
\hline TRINITY_DN104142_c1_g2 & down & -1.48 & - & alcohol dehydrogenase \\
\hline TRINITY_DN105737_c1_g2 & down & -1.02 & - & $\begin{array}{l}\text { peroxisomal fatty acid beta-oxidation } \\
\text { multifunctional protein }\end{array}$ \\
\hline TRINITY_DN86802_c1_g2 & down & -1.02 & - & acyl-coenzyme A oxidase 4 \\
\hline TRINITY_DN94419_c0_g1 & down & -1.08 & - & 3-ketoacyl-CoA thiolase \\
\hline TRINITY_DN96643_c0_g2 & up & 1.04 & 1.08 & $\begin{array}{l}\text { glyoxysomal fatty acid beta-oxidation } \\
\text { multifunctional protein }\end{array}$ \\
\hline TRINITY_DN91111_c0_g1 & down & - & -2.16 & Alcohol dehydrogenase class-3 \\
\hline TRINITY_DN100169_c0_g1 & down & - & -1.57 & Transcription factor MYB96 \\
\hline
\end{tabular}


Table 3

Summary of transcriptome sequencing

\begin{tabular}{|lllllll|}
\hline Sample & Read number & Base number & Raw reads & Clean reads & GC (\%) & \% QQ30 \\
\hline C & 35958230.67 & 10787469200 & 28950352.67 & 27874338.33 & 49.13 & 90.53 \\
\hline MS & 48581810.67 & 14574543200 & 34351135 & 32565016 & 48.85 & 91.61 \\
\hline S & 36788206 & 11036461800 & 33809654.67 & 32178793.33 & 49.06 & 90.91 \\
\hline
\end{tabular}

Table 4

Statistical table of assembly results

\begin{tabular}{|lll|}
\hline Length Range & Transcript & Unigene \\
\hline $300-500$ & $120199(37.09 \%)$ & $64100(45.08 \%)$ \\
\hline $500-1000$ & $103716(32.00 \%)$ & $44242(31.11 \%)$ \\
\hline $1000-2000$ & $67619(20.86 \%)$ & $22993(16.17 \%)$ \\
\hline $2000+$ & $32547(10.04 \%)$ & $10856(7.63 \%)$ \\
\hline Total Number & 324081 & 142191 \\
\hline Total Length & 310385290 & 119471125 \\
\hline N50 Length & 1327 & 1112 \\
\hline Mean Length & 957.74 & 840.22 \\
\hline
\end{tabular}

Figures 


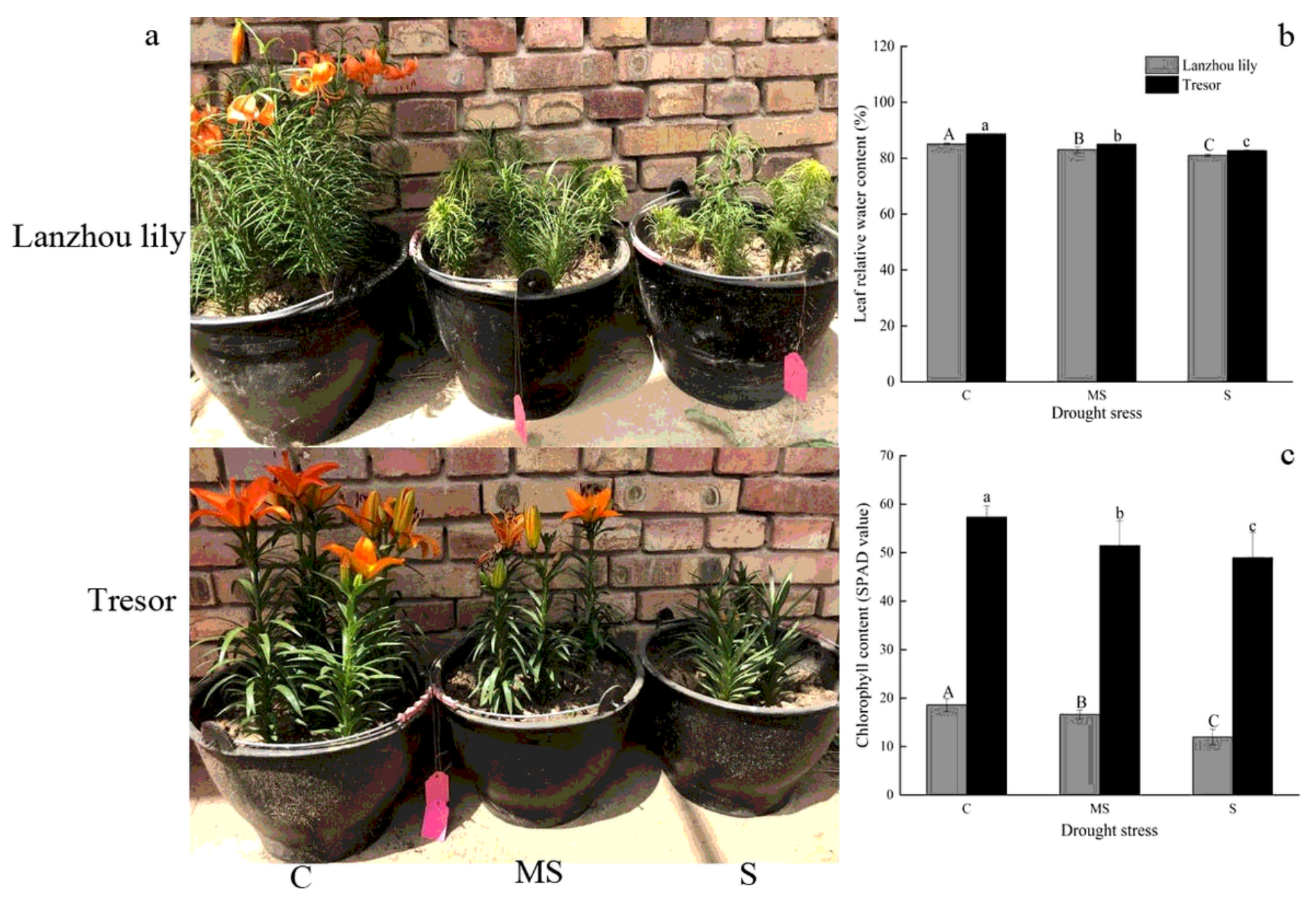

\section{Figure 1}

The leaf relative water content and chlorophyll content (SPAD value) of Lanzhou lily and Tresor under different drought stress. Values are the means $\pm S D(n=15)$. Parameter values followed by different letters represent a significant differenced, capital letters and lowercase letters represent Lanzhou lily and Tresor lily, respectively (ANOVA followed by Duncan's multiple-range tests $(P<0.05)$ ). Drought stress: $C$, control; MS, moderate severe; S, severe. 


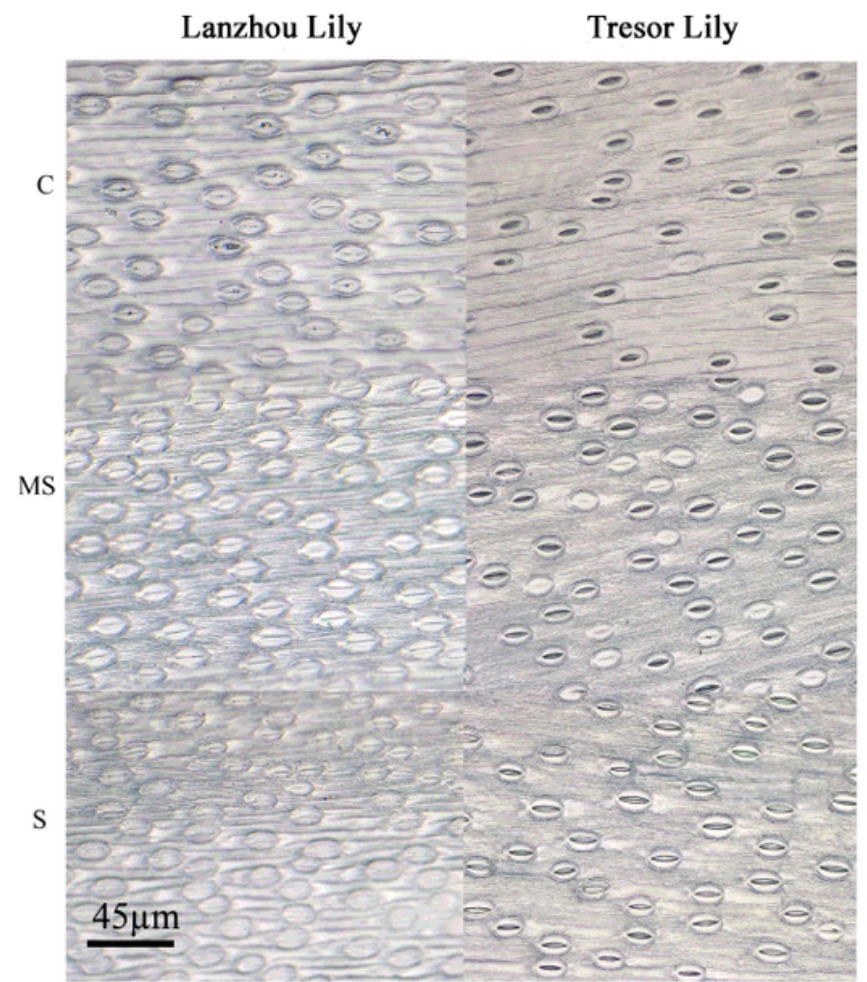

(A)

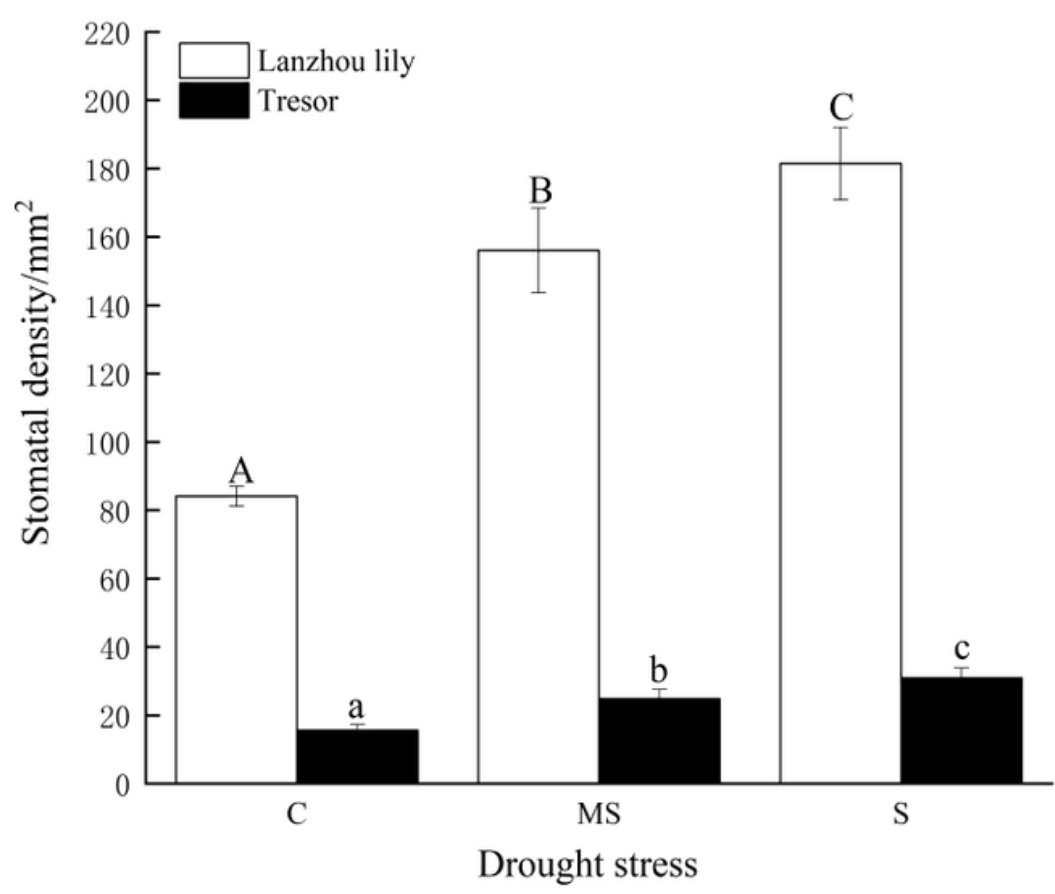

(B)

\section{Figure 2}

Stomatal apertures of the two of two lily genotypes (A) and stomatal density (B) under different drought stress. Parameter values followed by different letters represent a significant difference; capital letters and lowercase letters represent the Lanzhou lily and the Tresor lily, respectively $(P<0.05)$. Drought stress: $C$, control; MS, moderate severe; S, severe.

Lanzhou lily

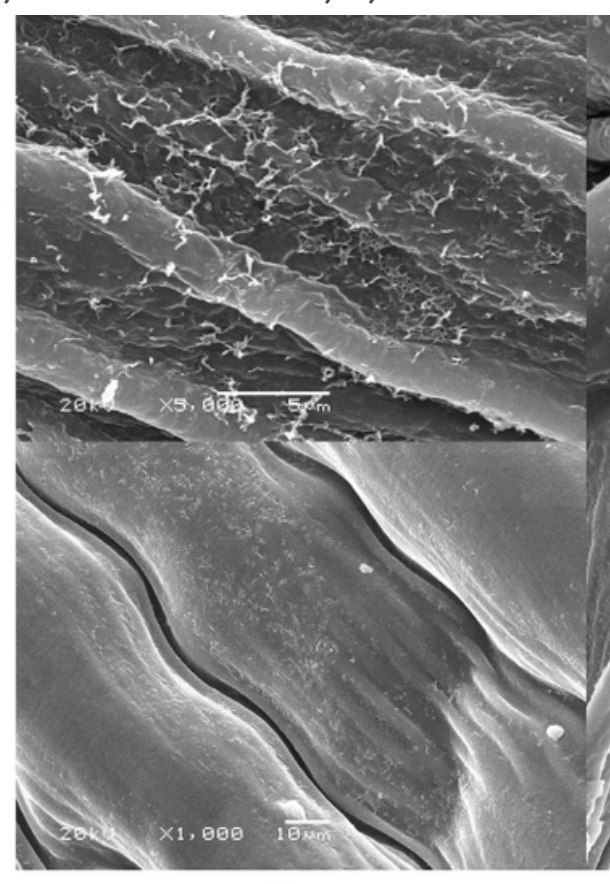

$\mathrm{C}$

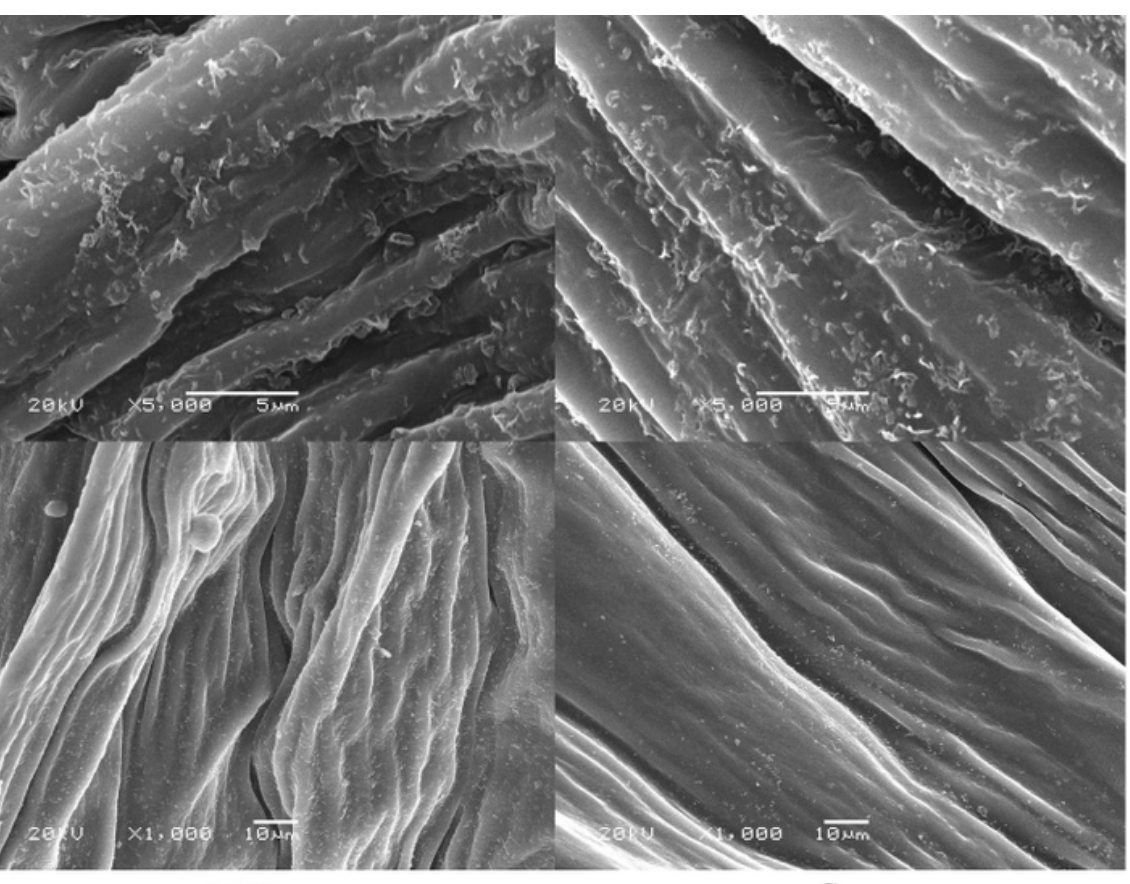

MS
S

Figure 3 
Scanning electron micrograph analysis of epicuticular wax crystal structure on leaves of Lanzhou lily and Tresor lily $(10 \mu \mathrm{m})$. Drought stress: C, control; MS, moderate severe; S, severe.
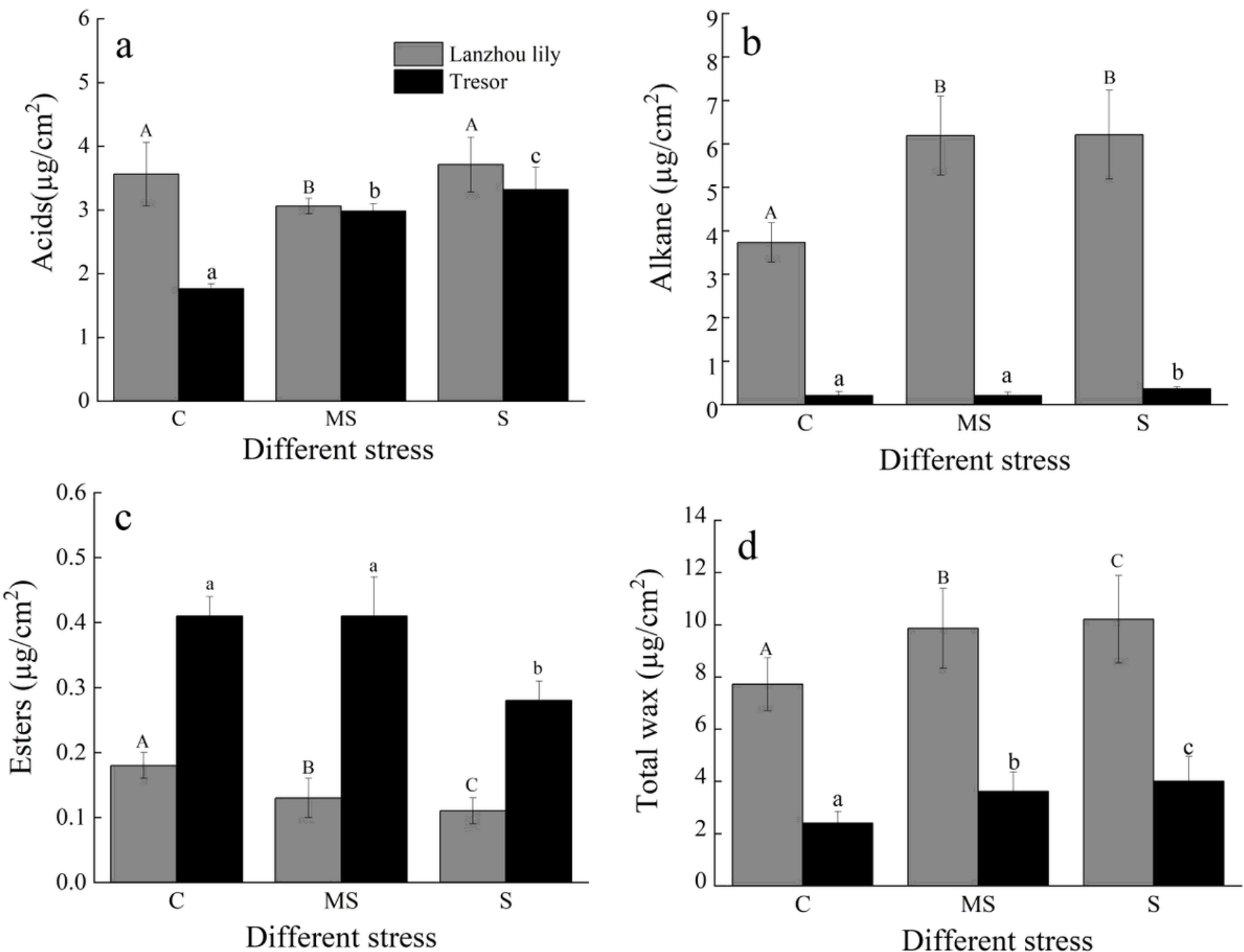

Figure 4

The content of wax components in the leaves of Lanzhou lily and Tresor lily under drought stress. (a) Acids; (b) Alkane; (c) Eeters; (d) Total wax. Values are the means \pm SD $(n=15)$. Parameter values followed by different letters represent a significant differenced, capital letters and lowercase letters represent Lanzhou lily and Tresor lily, respectively (ANOVA followed by Duncan's multiple-range tests $(\mathrm{P}<$ 0.05)). Drought stress: C, control; MS, moderate stress; S, severe stress. 
C_vs_MS

C_vs_S

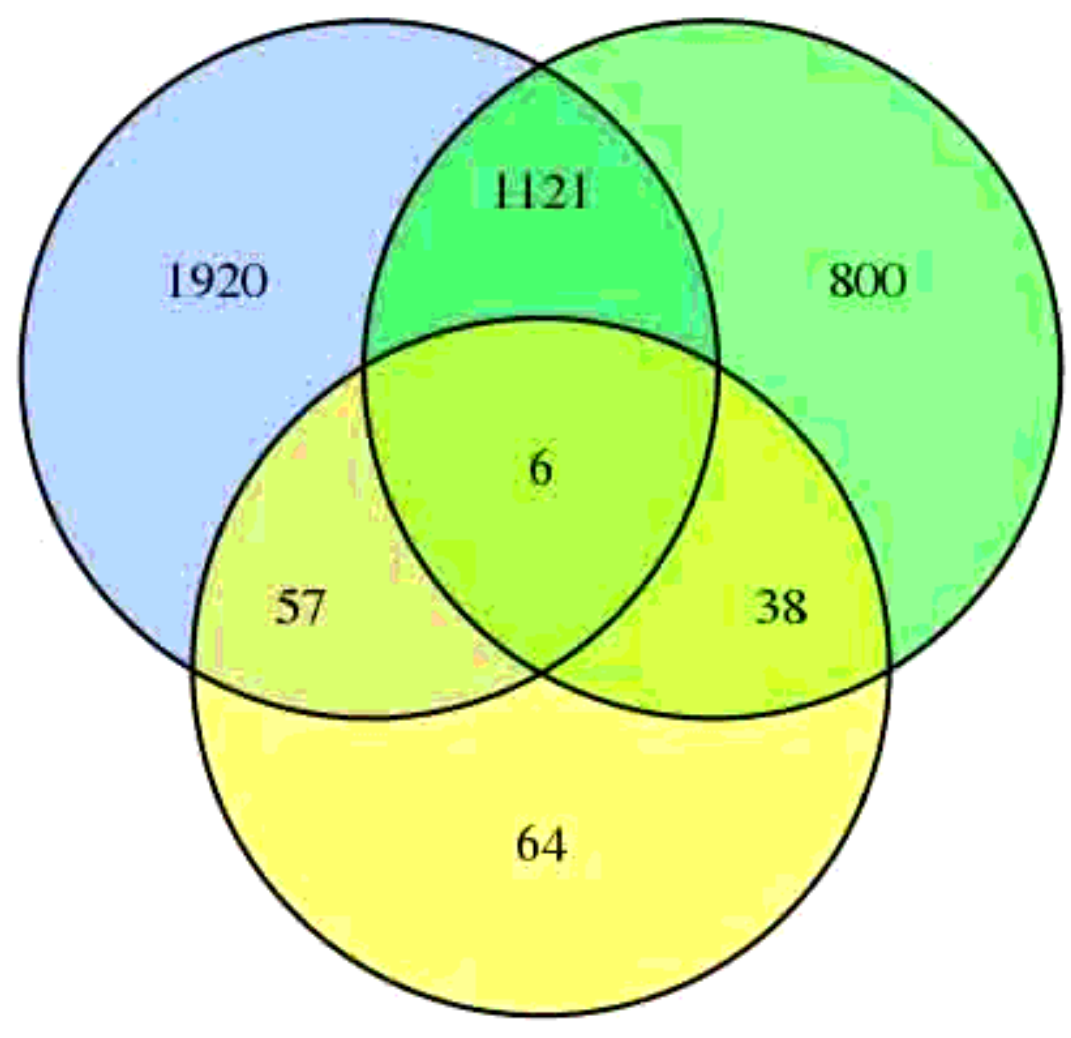

MS_vs_S

\section{Figure 5}

Venn diagram of differentially expressed genes of Lanzhou lily was under different drought stress.

Drought stress: C, control; MS, moderate severe; S, severe. DEGs were identified using a threshold of FDR $<0.05$ and $\mid \log 2$ (fold change) $\mid \geq 1$. 


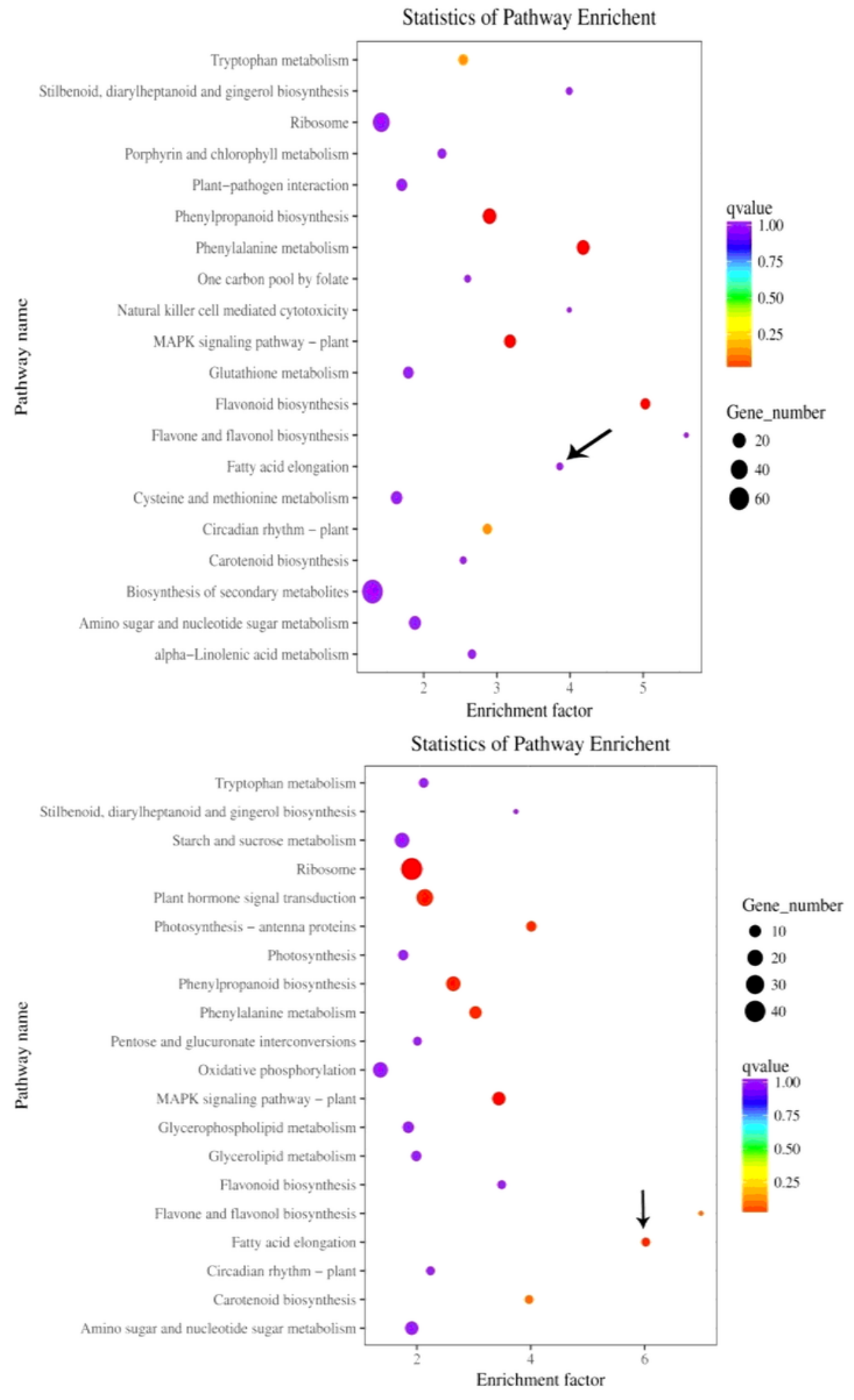

Figure 6

KEGG pathway enrichment analysis of leaves drought response DEGs on Lanzhou lily. (A) C vs. MS; (B) C vs. S Drought stress: C, control; MS, moderate severe; S, severe. 


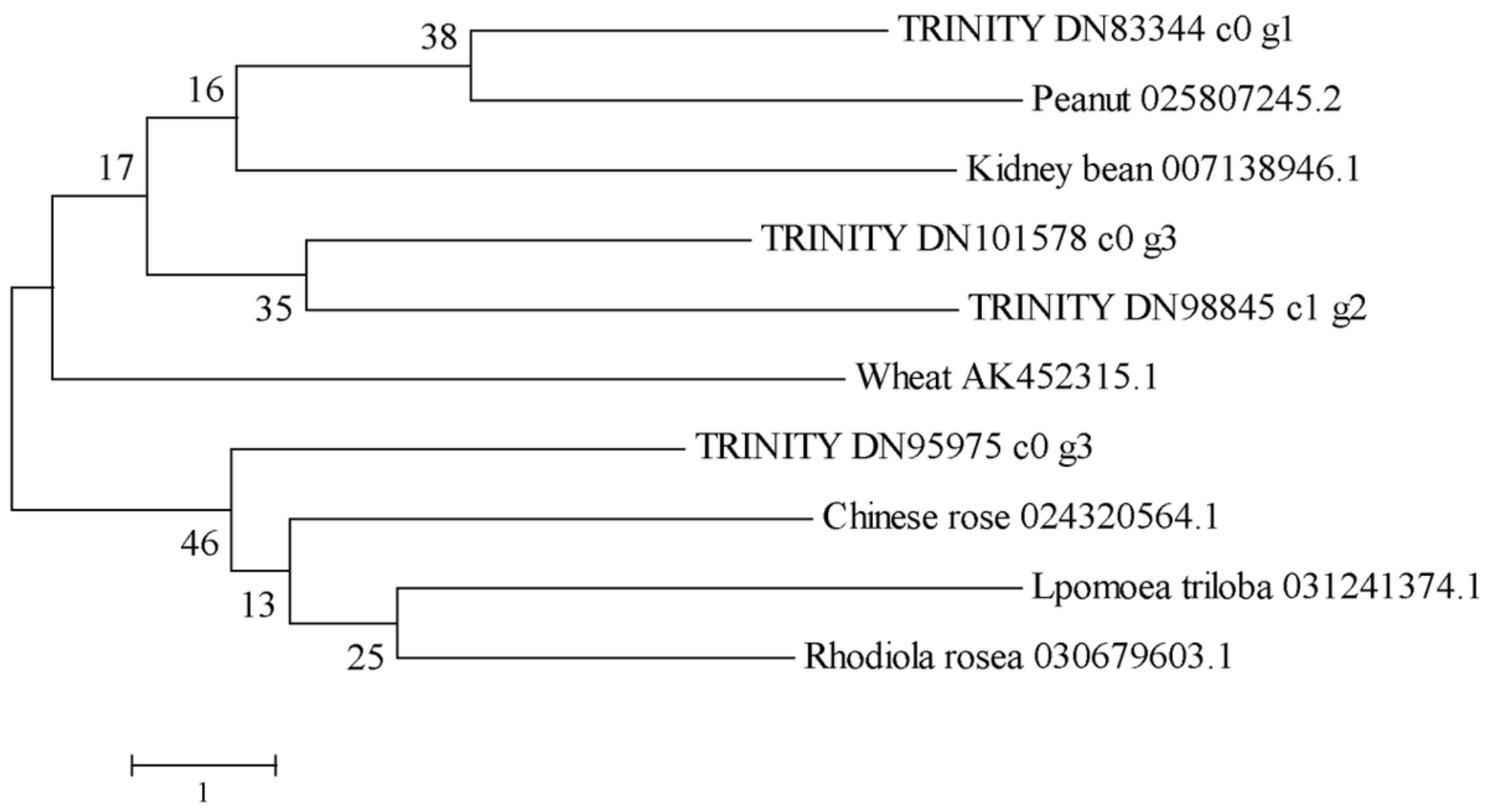

\section{Figure 7}

Phylogenetic relationships of KCS gene in different species based on amino acid sequences. The number of branching sites represents the posterior probability of node support.
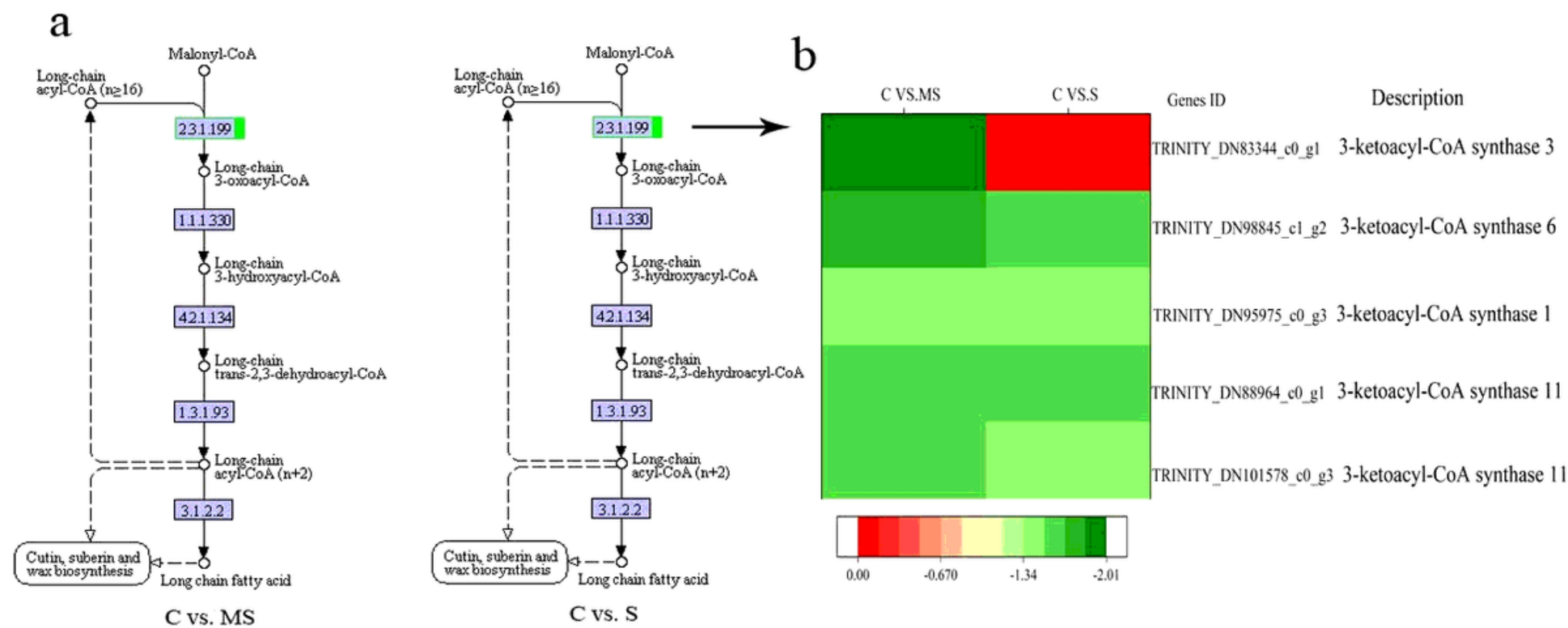

\section{Figure 8}

Transcriptome diagram of fatty acid biosynthesis pathway regulation in Lanzhou lily leaves under drought stress (a) and heat map of differentially expressed transcripts (b). The number in the box represents the EC and the green indicates that the expression of inhibited enzymes in Lanzhou lily leaves. 